\title{
FREQUENCY OF DYSLIPIDEMIA IN PATIENTS WITH TYPE II DIABETES MELLITUS PRESENTING IN DHQ TEACHING HOSPITAL, SAHIWAL.
}

1. MBBS

Medical Officer/PGR Medicine

DHQ Teaching Hospital, Sahiwal.

2. MBBS, MCPS, FCPS

Associate Professor Medicine

Sahiwal Medical College, Sahiwal.

3. MBBS, MPH

Associate Professor Community Medicine

Sahiwal Medical College, Sahiwal.

4. MBBS, FCPS

Senior Registrar Surgery

Civil Hospital, Bahawalpur.

Correspondence Address:

Dr Rana Aamir Diwan

Department of Community Medicine

Sahiwal Medical College, Sahiwal.

aamirdiwan@yahoo.com

Article received on:

23/09/2019

Accepted for publication:

05/12/2019

\begin{abstract}
Abbas Humayun', Khalil Ahmad², Rana Aamir Diwan ${ }^{3}$, Muhammad Saiful Malook ${ }^{4}$
\end{abstract}
ABSTRACT... Dyslipidemia is major risk factor for cardiovascular disease in diabetes mellitus (DM). Early detection and treatment of dyslipidemia in type 2 DM can prevent the risk for atherosclerosis. Objectives: To determine the frequency of dyslipidemia in patients with type 2 diabetes mellitus presenting in DHQ Teaching Hospital, Sahiwal for routine checkup. Study Design: Cross Sectional, Observational, Descriptive study. Setting: Medical Unit 1, DHQ Teaching Hospital, Sahiwal, Pakistan. Period: 05-05-2018 to 05-11-2018. Material \& Methods: Total 180 patients fulfilling selection criteria were enrolled in the study. Blood samples were obtained and sent to the Pathology Laboratory of the hospital for assessment of lipid profile. Reports were assessed and if cholesterol $>200 \mathrm{mg} / \mathrm{dl}$ and triglyceride $>150 \mathrm{mg} /$ $\mathrm{dl}$, then dyslipidemia was labeled. All this information was recorded on pro-formas. Results: In this study dyslipidemia was diagnosed in $81(45 \%)$ patients. Frequency of dyslipidemia was higher in age group 51-60 years (44.4\%) as well as among female patients (56.8\%). Overweight patients and patients with normal BMI had the highest frequency of dyslipidemia. Conclusion: the results of this study showed high frequency of dyslipidemia among type II diabetic patients. Type II diabetes is very much common in our population so there is a need to design screening programs in which blood lipid levels screening should be monitored on regular intervals to rule out dyslipidemia timely and for effective and proper management with statin therapy.

Key words: Cardiovascular Disorders, Dyslipidemia, Lipid Profile, Type II Diabetes Mellitus.

Article Citation: Humayun A, Ahmad K, Diwan RA, Malook MS. Frequency of dyslipidemia in patients with type ii diabetes mellitus presenting in DHQ Teaching Hospital, Sahiwal. Professional Med J 2020; 27(7):1433-1437.

DOI: 10.29309/TPMJ/2020.27.07.4198

\section{INTRODUCTION}

Type II diabetes mellitus and its complications are the major and growing public health problem around the world including developing countries. ${ }^{1}$ The frequency of Type II diabetes is increasing at a fast pace in South Asian countries due to high level of Insulin resistance, upper body adiposity, high genetic predisposition, a high body fat percentage, high level of insulin resistance and higher BMI in general population. ${ }^{2}$

Diabetes is associated with high incidence of dyslipidemia with elevated level of low density lipoprotein (LDL), cholesterol and triglyceride. ${ }^{3}$ Presence of lipoprotein disorders is a very common finding in diabetic patients and is the major contributor to the morbidity and mortality from cardiovascular diseases. According to ATP
111 guidelines, diabetic dyslipidemia is defined by the presence of high serum total cholesterol, high serum triglyceride, high LDL and low serum HDL in Type II diabetes patients. ${ }^{4}$

Dyslipidemia is major risk factor for cardiovascular disease in Type 2 diabetes. Early detection and treatment of dyslipidemia in Type 2 diabetes can prevent risk for atherosclerosis. ${ }^{2}$

In Nepal, the prevalence of dyslipidemia among Type II diabetes patients was $85.33 \% .^{5}$ In Rawalpindi, the frequency of dyslipidemia was $80 \%$ among diabetic patients. ${ }^{6}$ In DG Khan, it was observed among diabetic patients dyslipidemia was found in $74 \%$ patients. ${ }^{7}$ Mehmood $\mathrm{F}$ et al., found in Multan that dyslipidemia is present in $81.5 \%$ diabetic patients. ${ }^{8}$ While one study 
conducted in Faisalabad, the frequency of dyslipidemia was found in $17 \%$ among diabetic patients. $^{9}$

Rationale of this study is to determine the frequency of dyslipidemia in patients with Type 2 DM presenting in a tertiary care hospital for routine check-up. Through literature, it has been noticed that the risk of dyslipidemia is very high in patients of Type 2 DM. But controversial results have been noticed in locally conducted studies as mentioned above. Moreover, there is no study found that would be conducted in Sahiwal region. So we want to conduct this study to find the extent of problem in local population. So that early steps can be taken in screening and management of Type 2 diabetes patients to prevent them from developing dyslipidemia. This will help to get local evidence and we will be able to recommend that lipid profile of Type II diabetes patients should be screened on regular intervals to prevent the dyslipidemia as it worsen the quality of life of patients and may lead to cardiovascular and cerebrovascular complications.

\section{OBJECTIVE}

The objective of this study was to determine the frequency of dyslipidemia in Type 2 Diabetes mellitus patients presenting to a tertiary care hospital for routine check-up.

\section{MATERIAL \& METHODS}

This was a Cross sectional, observation, descriptive study conducted at Unit 1, Department of Medicine, DHQ Hospital, Sahiwal from 5-52018 to 5-11-2018.

The sample size of 180 patients was calculated with $95 \%$ confidence level, $6 \%$ margin of error and taking expected percentage of dyslipidemia i.e. $17 \%$ in patients with Type II diabetes mellitus. Non-probability, consecutive sampling technique was used.

Patients of age 40-70years of either gender presenting with Type II diabetes mellitus (It was defined as BSR>186mg/dl for >1year and patient is taking anti-glycemic medication) for routine check-up diagnosed at least 1 year ago were included in the study. Following patients were excluded from the study.

1. Patients with co-morbid conditions i.e. liver disease (ALT>40IU, AST>40IU), renal problems (Creatinine $>1.2 \mathrm{gm} / \mathrm{dl}$ ), Anemia $(\mathrm{Hb}<10 \mathrm{~g} / \mathrm{dl})$, Thyroid Problem (TSH $>5 \mathrm{IU} / \mathrm{L})$

2. Patients already taking statins (medical record)

3. Smokers ( $>5$ pack year)

4. Morbidly obese $(\mathrm{BMI}>35 \mathrm{~kg} / \mathrm{m} 2)$

A total of 180 patients fulfilling selection criteria were enrolled in the study through OPD of Department of Medicine, DHQ Hospital, Sahiwal. Informed consent was obtained. Demographic information (name, age, gender, BMl, h/o hypertension $[B P \geq 140 / 90 \mathrm{mmHg}]$, duration of diabetes) was also obtained. Then blood samples were obtained by using 3cc BD syringe with the help of a staff nurse. All samples were stored in sterile containers and sent to the Pathology Laboratory of the hospital for assessment of lipid profile. Reports were assessed and if cholesterol>200mg/dl and triglyceride>150mg/ $\mathrm{dl}$, then dyslipidemia was labeled. All this information was recorded on the pro-formas. The data collected was entered into SPSS version 21.0 and analyzed. Quantitative variables like age, BMI and duration of diabetes was calculated at Mean \& Standard Deviation. Qualitative variable like gender, hypertension and dyslipidemia was calculated as frequency and percentage. Data was stratified for age, gender, BMI, hypertension $(B P>160 / 90)$ and duration of diabetes.

\section{RESULTS}

The mean age of patients in this study was $52.87 \pm 7.54$ years. Minimum and maximum age of patients was 40 and 65 years.

Among patients $88(48.9 \%)$ were male and 92(51.1\%) were female.

As per BMI criteria $47(26.1 \%)$ patients were obese, $58(32.2 \%)$ were overweight and $75(41.7 \%)$ patient's BMI was normal.

Mean duration of diabetes was $18.17 \pm 3.84$ months. 
Among all patients 87(48.35\%) were hypertensive.

The meantotal cholesterol was $231.97 \pm 118.63 \mathrm{mg} /$ $\mathrm{dl}$ and mean triglycerides was $185.10 \pm 85.06 \mathrm{mg} /$ dl. Thus dyslipidemia was diagnosed in $81(45 \%)$ patients.

Insignificant association was seen between age of patients and frequency of dyslipidemia i.e. p-value $=0.440$. Table-l.

\begin{tabular}{|l|c|c|c|}
\hline \multirow{2}{*}{ Age } & \multicolumn{2}{|c|}{ Dyslipidemia } & \multirow{2}{*}{ Total } \\
\cline { 2 - 4 } & Yes & No & \\
\hline $40-50$ & $32(39.5 \%)$ & $41(41.4 \%)$ & 73 \\
\hline $51-60$ & $36(44.4 \%)$ & $36(36.4 \%)$ & 72 \\
\hline$>65$ & $13(16 \%)$ & $22(22.2 \%)$ & 35 \\
\hline Total & 81 & 99 & 180 \\
\hline
\end{tabular}

Table-I. Dyslipidemia among Type 2 Diabetic Patients stratified for age of patients

Chi-Square Test $=1.640$ - $p$-value $=0.440$

Although among female patients frequency of dyslipidemia was higher as compared to male patients but it was not statistically significant i.e. Male: $43.2 \%$ \& Female: $56.8 \%$, p-value $=0.168$. Table-II

\begin{tabular}{|l|c|c|c|}
\hline \multirow{2}{*}{ Gender } & \multicolumn{2}{|c|}{ Dyslipidemia } & \multirow{2}{*}{ Total } \\
\cline { 2 - 3 } & Yes & No & \\
\hline Male & $35(43.2 \%)$ & $53(53.5 \%)$ & 88 \\
\hline Female & $46(56.8 \%)$ & $46(46.5 \%)$ & 92 \\
\hline Total & 81 & 99 & 180 \\
\hline
\end{tabular}

Table-II. Dyslipidemia among Type 2 diabetic patients stratified for gender of patients

Chi-Square Test $=1.901-p$-value $=0.168$

BMI index have no significant impact on frequency of dyslipidemia. However the highest frequency of dyslipidemia was seen in patients who were overweight. Table-III

\begin{tabular}{|l|c|c|c|}
\hline \multirow{2}{*}{\multicolumn{1}{|c|}{ BMI }} & \multicolumn{2}{c|}{ Dyslipidemia } & \multirow{2}{*}{ Total } \\
\cline { 2 - 3 } & Yes & No & \\
\hline Normal & $27(33.3 \%)$ & $48(48.5 \%)$ & 75 \\
\hline Overweight & $30(37 \%)$ & $28(28.3 \%)$ & 58 \\
\hline Obese & $24(29.6 \%)$ & $23(23.2 \%)$ & 47 \\
\hline Total & 81 & 99 & 180 \\
\hline
\end{tabular}

Table-III. Dyslipidemia among Type 2 diabetic patients stratified for BMI of patients

Chi-Square Test $=4.212$ - $p$-value $=0.122$
Insignificant difference was seen for frequency of dyslipidemia among hypertensive and nonhypertensive patients. Table-IV

\begin{tabular}{|l|c|c|c|}
\hline \multirow{2}{*}{ Hypertension } & \multicolumn{2}{|c|}{ Dyslipidemia } & \multirow{2}{*}{ Total } \\
\cline { 2 - 4 } & Yes & No & \\
\hline Yes & $38(46.9 \%)$ & $49(49.5 \%)$ & 87 \\
\hline No & $43(53.1 \%)$ & $50(50.5 \%)$ & 93 \\
\hline Total & 81 & 99 & 180 \\
\hline \multicolumn{2}{|c|}{ Table-IV. Dyslipidemia among Type 2 status of } \\
patients
\end{tabular}

Insignificant difference was seen for frequency of dyslipidemia in relation to duration of diabetes i.e. $p$-value $=0.650$. Table- $V$

\begin{tabular}{|c|c|c|c|}
\hline \multirow{2}{*}{$\begin{array}{l}\text { Duration of } \\
\text { Diabetes }\end{array}$} & \multicolumn{2}{|c|}{ Dyslipidemia } & \multirow{2}{*}{ Total } \\
\hline & Yes & No & \\
\hline $12-16$ & $27(33.3 \%)$ & $39(39.4 \%)$ & 66 \\
\hline $17-20$ & $29(35.8 \%)$ & $30(30.3 \%)$ & 59 \\
\hline $21-24$ & $25(30.9 \%)$ & $30(30.3 \%)$ & 55 \\
\hline Total & 81 & 99 & 180 \\
\hline \multicolumn{4}{|c|}{$\begin{array}{c}\text { Table-V. Dyslipidemia among Type-2 diabetic patients } \\
\text { stratified for duration of diabetes } \\
\text { Chi-Square Test }=0.862 \text { p-value }=0.650\end{array}$} \\
\hline
\end{tabular}

\section{DISCUSSION}

Dyslipidemia as a metabolic abnormality has a strong association with DM. Its prevalence is variable due to depenendence on the type and severity of DM, glycaemic control, nutritional status, age of the patients and other variables. Previous studies have shown a strong clustering risk factor for cardiac disease in diabetic patients. ${ }^{10,11}$ One or more types of dyslipidemia are present in about $70 \%$ of patients of DM Type-2 patients. In this study dyslipidemia was diagnosed in $81(45 \%)$ patients. Frequency of dyslipidemia was higher in age group 51-60 years (44.4\%) as well as among female patients (56.8\%). Overweight patients and patients with normal $\mathrm{BMI}$ had the highest frequency of dyslipidemia. In Nepal, the prevalence of dyslipidemia among Type II diabetes patients was $85.33 \% .^{5}$ In this study frequency of dyslipidemia was almost half as that of reported in study from Nepal. In Rawalpindi, the frequency of dyslipidemia was 
$80 \%$ among diabetic patients. ${ }^{6}$ In DG Khan, it was observed among diabetic patients dyslipidemia was found in $74 \%$ patients. ${ }^{7}$ Mehmood $\mathrm{F}$ et al., found in Multan that dyslipidemia is present in $81.5 \%$ diabetic patients. ${ }^{8}$

In this study, the frequency of dyslipidemia was much lower when it was compared with above mentioned local study. This difference may be due to difference in the study sample size or other methodological considerations. However the study conducted in Faisalabad found out the lower frequency of dyslipidemia as that of this study. i.e. $17 \%$ among diabetic patients. ${ }^{9}$

An observational study which was conducted among Chinese adults indicated that women had a higher dyslipidemia risk (Odds Ratio:1.51with 95\% Confidence interval: 1.25-1.83). ${ }^{12}$ The same trend was seen in this study that higher frequency of dyslipidemia was seen in diabetic female patients. Previous studies have reported higher provenance among men than in women which contradicts the findings of this study. ${ }^{13,14}$ Indian studies have also reported higher frequency of dyslipidemia in hyperglycemic patients (89$92.4 \%){ }^{15,16}$

The inter-relationship of carbohydrates and lipids metabolism affects blood lipids in patients of diabetes. Therefore, any disorder in carbohydrate metabolism can make changes in lipid metabolism and vice versa. ${ }^{17}$ Insulin resistance is a primary defect in the majority patients with type-2 DM. In the case of non-diabetic patients, insulin resistance along with hyperinsulinemia has a high risk for future development of type-2 DM. ${ }^{18}$ Multiple studies have shown that insulin affects the liver production of apolipoprotein. It also regulates the enzymatic activity of lipoprotein lipase and cholesterol ester transport protein, which leads to dyslipidemia in DM. The activity of hepatic lipase is decreased due to the deficiency of insulin leading to inefficiency in the production of biologically-active lipoprotein lipase. ${ }^{19,20}$

Dyslipidemia management in people with DM begins with a thorough assessment in order to identify secondary causes. As these causes lead to the abnormality in the lipid profile. ${ }^{21}$ Lifestyle changes such as increased physical activity and dietary changes, is the mainstay of treatment. All efforts should be made to bring the blood glucose levels to normal in the poorly controlled patients of DM. The better control of blood glucose level will lead to improvement of the dyslipidemia. ${ }^{22}$

\section{CONCLUSION}

The results of this study showed high frequency of dyslipidemia among type-2 diabetic patients. As Type-2 diabetes is very much common in our population, so there is a need to design screening programs in which blood lipid levels screening should be monitored on regular intervals to rule out dyslipidemia timely and for effective and proper management with statin therapy.

\section{Copyright 05 Dec, 2019.}

\section{REFERENCES}

1. 1. Ahmida M, Gatish Z, Al-Badry S, El-Shalmani I, ElDeeb $O$. Dyslipidemia in type 2 diabetes mellitus patients in Benghazi, Libya. Int $\mathrm{J}$ Biomed Adv Res 2015; 6(10):749-53.

2. 2. Dixit AK, Dey R, Suresh $A$, Chaudhuri S, Panda AK, Mitra $A$, et al. The prevalence of dyslipidemia in patients with diabetes mellitus of ayurveda Hospital. J Diab Metab Disord 2014; 13(1):58.

3. 3. Thapa SD, KC SR, Gautam S, Gyawali D. Dyslipidemia in type 2 diabetes mellitus. J Pathol Nepal 2017; 7(2):1149-54.

4. 4. Gilani SYH, Bibi S, Ahmed N, Shah SRA. Gender differences of dyslipidemia in type 2 diabetics. $J$ Ayub Med Coll Abbottabad 2010; 22(3):146-8.

5. Shrestha HK, Khanal L. Prevalence and pattern of dyslipidemia among type 2 diabetes mellitus patients in a Tertiary Center Hospital of Nepal. Endocrinol Metab Int J 2017; 4(3):00084.

6. Khan AU, Yasmeen R, Ahmed W, lqbal M, Uttra KM. Frequency of dyslipidemia in type-2 diabetes mellitus patients. Pak Armed Forces Med J 2011; 61(4).

7. Javed RA, Bhatti A, AMIN MRU. Dyslipidemia in type 2 diabetes mellitus in normal and underweight patient. Pak J Med Health Sci 2016; 10(2):568-70.

8. Mehmood F, Ahmed S, Alamgir W, Ali S. Frequency of dyslipidemias in diabetic patients at Combined Military Hospital Multan. Pak Armed Forces Med J $2011 ; 61: 354-7$ 
9. Sarfraz M, Sajid S, Ashraf MA. Prevalence and pattern of dyslipidemia in hyperglycemic patients and its associated factors among Pakistani population. Saudi J Biol Sci 2016; 23(6):761-6.

10. Brinck JW, Thomas A, Lauer E, Jornayvaz FR, BrulhartMeynet $\mathrm{M}-\mathrm{C}$, Prost $\mathrm{J}-\mathrm{C}$, et al. Diabetes mellitus is associated with reduced high-density lipoprotein sphingosine-1-phosphate content and impaired high-density lipoprotein cardiac cell protection. Arteriosclerosis, thrombosis, and vascular biology 2016; 36(5):817-24.

11. Regmi P, Gyawali P, Shrestha R, Sigdel M, Mehta KD, Majhi S. Pattern of dyslipidemia in type-2 diabetic subjects in Eastern Nepal. J Nepal Assoc Med Lab Sci 2009; 10(1):11-3.

12. Wang S, Xu L, Jonas JB, You QS, Wang YX, Yang $H$. Prevalence and associated factors of dyslipidemia in the adult Chinese population. PloS one 2011; 6(3):e17326.

13. Li $Y$, Zhao $L, Y u D$, Ding $G$. The prevalence and risk factors of dyslipidemia in different diabetic progression stages among middle-aged and elderly populations in China. PloS one 2018; 13(10):e0205709.

14. Pan L, Yang Z, Wu Y, Yin R-X, Liao Y, Wang J, et al. The prevalence, awareness, treatment and control of dyslipidemia among adults in China. Atherosclerosis 2016; 248:2-9.
15. Udawat $H$, Goyal R, Maheshwari S. Coronary risk and dyslipidemia in type 2 diabetic patients. The Journal of the Association of Physicians of India 2001; 49:970-3.

16. Jayarama N, Reddy M, Lakshmaiah V. Prevalence and pattern of dyslipidemia in Type 2 diabetes mellitus patients in a rural tertiary care centre, southern India 2012.

17. Chatterjea M, Shinde R. Textbook of medical biochemistry: Wife Goes On; 2011.

18. Haffner S, Mykkanen L, Festa A, Burke J, Stern M. Insulin resistant prediabetic subjects have more atherogenic risk factors than insulin sensitive prediabetic subjects. Diabetes 1999; 48(5):SA70-SA.

19. Mooradian AD. Dyslipidemia in type 2 diabetes mellitus. Nature Reviews Endocrinology 2009; 5(3):150.

20. Smith S, Lall AM. A Study on lipid profile levels of diabetics and non-diabetics among Naini region of Allahabad, India. 2008.

21. Hachem SB, Mooradian AD. Familial dyslipidaemias: An overview of genetics, pathophysiology and management. Drugs [Research Support, Non-U S Gov't Review] 2006; 66(15):1949-69.

22. Siraj ES, Seyoum B, Saenz C, Abdulkadir J. Lipid and lipoprotein profiles in Ethiopian patients with diabetes mellitus. Metabolism 2006; 55(6):706-10.

\section{AUTHORSHIP AND CONTRIBUTION DECLARATION}

\begin{tabular}{|c|c|c|c|}
\hline Sr. \# & Author(s) Full Name & Contribution to the paper & Author(s) Signature \\
\hline 1 & Abbas Humayun & $\begin{array}{l}\text { Main author, Manuscripts designing, } \\
\text { Discussion writing, Data collection. }\end{array}$ & \\
\hline 2 & Khalil Ahmad & $\begin{array}{l}\text { Supervision of data collection, } \\
\text { Literature review. }\end{array}$ & \\
\hline 3 & Rana Aamir Diwan & Authentication of references, Critical & \\
\hline 4 & M. Saiful Malook & $\begin{array}{l}\text { Data analysis, Designing of charts/ } \\
\text { tablers. }\end{array}$ & srit \\
\hline
\end{tabular}

